Table 1. Genotype and allele frequencies of NCF2, NCF4, CYBA genes polymorphisms in RA patients and controls [n(\%)]

\begin{tabular}{|c|c|c|c|c|c|}
\hline SNP & Analyze model & & $\mathrm{RA}(\mathrm{N}=593)$ & Control $(\mathrm{N}=596)$ & $P$ value \\
\hline \multicolumn{6}{|l|}{ NCF2 } \\
\hline \multirow[t]{5}{*}{ rs10911363 } & Genetypes & GG & 125 & 144 & 0.371 \\
\hline & & GT & 304 & 289 & 0.747 \\
\hline & & TT & 164 & 163 & \\
\hline & Alleles & $\mathrm{G}$ & 554 & 577 & 0.408 \\
\hline & & $\mathrm{T}$ & 632 & 615 & \\
\hline \multicolumn{6}{|l|}{ NCF4 } \\
\hline \multirow[t]{5}{*}{ rs1883112 } & Genetypes & GG & 57 & 56 & 0.972 \\
\hline & & GA & 248 & 255 & 0.754 \\
\hline & & AA & 288 & 285 & \\
\hline & Alleles & G & 362 & 367 & 0.888 \\
\hline & & A & 824 & 825 & \\
\hline \multirow{7}{*}{ rs 4821544} & Genetypes & $\mathrm{CC}$ & 4 & 7 & 0.323 \\
\hline & & $\mathrm{CT}$ & 117 & 146 & 0.043 \\
\hline & & $\mathrm{TT}$ & 472 & 443 & \\
\hline & Alleles & C & 125 & 160 & 0.031 \\
\hline & & $\mathrm{T}$ & 1061 & 1032 & \\
\hline & Dominant model & TT & 472 & 443 & 0.031 \\
\hline & & $\mathrm{CT}+\mathrm{CC}$ & 121 & 153 & \\
\hline \multirow[t]{5}{*}{ rs729749 } & Genetypes & TT & 104 & 102 & 0.445 \\
\hline & & CT & 266 & 302 & 0.033 \\
\hline & & $\mathrm{CC}$ & 223 & 192 & \\
\hline & Alleles & $\mathrm{T}$ & 474 & 506 & 0.219 \\
\hline & & C & 712 & 686 & \\
\hline \multicolumn{6}{|l|}{$C Y B A$} \\
\hline \multirow[t]{5}{*}{ rs3794624 } & Genetypes & AA & 14 & 15 & 0.929 \\
\hline & & $\mathrm{GA}$ & 160 & 147 & 0.368 \\
\hline & & GG & 419 & 43 & \\
\hline & Alleles & A & 188 & 177 & 0.498 \\
\hline & & G & 998 & 1015 & \\
\hline \multirow[t]{5}{*}{ rs4673 } & Genetypes & AA & 1 & 5 & 0.140 \\
\hline & & GA & 85 & 90 & 0.673 \\
\hline & & $\mathrm{GG}$ & 507 & 501 & \\
\hline & Alleles & A & 87 & 100 & 0.34 \\
\hline & & G & 1099 & 1092 & \\
\hline
\end{tabular}

Acknowledgments: no

Disclosure of Interests: None declared

DOI: 10.1136/annrheumdis-2020-eular.4278

\section{AB0024 ASSOCIATION OF IL6 RS1800795 BUT NOT IL6R RS2228145, RS4845618 AND STAT4 RS7574865 POLYMORPHISMS WITH CHLAMYDIA-ASSOCIATED RHEUMATOID ARTHRITIS}

T. Zybalova ${ }^{1}$, V. Yagur $^{1}$, R. Goncharova ${ }^{2}$, N. Soroka ${ }^{1}$, N. Dostanko ${ }^{1}$, V. Apanasovich ${ }^{1}$, A. Tushina ${ }^{1} .{ }^{1}$ Belarusian State Medical University, 2-nd Department of Internal Medicine, Minsk, Belarus; ${ }^{2}$ Institute of Genetics \& Cytology NAS Belarus, Laboratory of Molecular Basis of Genomic Stability, Minsk, Belarus

Background: Rheumatoid arthritis (RA), associated with Chlamydial Infection, has some clinical and immunological particulars that interfere with the early diagnosis and require significant changes in treatment strategy [1].

Objectives: To estimate the distribution of some non-HLA genetic markers such as STAT4 rs7574865, IL6 rs1800795, IL6R rs2228145 and rs4845618 in Chlamydia positive and negative RA patients and healthy controls.

Methods: We examined 380 healthy blood donors and 187 RA patients classified according to the ACR/EULAR 2010 criteria for RA [2]. Twenty-three of the RA patients were positive for Chlamidia trachomatis $(n=17)$ or Chlamidia pneumonia $(n=6)$ persistence. DNA from peripheral blood samples was extracted by phenol-chloroform method. SNPs were genotyped by the real-time PCR with fluorescent probes. Statistical significance of SNPs' frequency was estimated by two-way Fisher exact test $\left(F, p_{2-t}\right)$ with Bonferroni correction for multiple comparisons $\left(\mathrm{p}_{\mathrm{cor}}\right)$. Moreover, diagnostic odds ratio (dOR), the likelihood ratio of positive $\left(\mathrm{LR}^{+}\right)$and negative $\left(\mathrm{LR}^{-}\right)$tests and corresponding confidence intervals $(\mathrm{Cl})$ were calculated.

Results: We revealed statistically significant increase of genotype CC frequency (IL6 rs 1800795) in Chlamydia-associated RA (60.9\%) vs healthy donors $(20.7 \%)$ : $p_{2-t}=0.000065 ; p_{\text {cor }}=0.00026 ;$ dOR=5.95 $\left(\mathrm{Cl}_{95 \%}\right.$ 2.53-13.94); LR ${ }^{+}=2.94\left(\mathrm{Cl}_{95 \%}\right.$ 1.90-3.29); $\mathrm{LR}^{-}=0.49\left(\mathrm{Cl}_{95 \%}\right.$ 0.28-0.75) as well as in Chlamydia-associated $\mathrm{RA}$ $(60.9 \%)$ vs Chlamydia-negative RA (23.9\%): $\mathrm{p}_{2 \mathrm{t}}=0.00051 ; \mathrm{p}_{\mathrm{cor}}=0.002 ; \mathrm{dOR}=4.99$ $\left(\mathrm{Cl}_{95 \%}\right.$ 2.04-12.16); $\mathrm{LR}^{+}=2.56\left(\mathrm{Cl}_{95 \%}\right.$ 1.60-3.57); LR $=0.51\left(\mathrm{Cl}_{95 \%} 0.29-0.78\right)$. Significant differences in STAT4 rs7574865, IL6R rs2228145 and IL6R rs4845618 distribution between studied groups were not found.

Conclusion: Our data suggest the association between CC genotype of IL6 rs1800795 and Chlamydia-associated RA.

References:

[1] Soroka N.F. Rheumatoid Arthritis, associated with Chlamydial infection // Healthcare 2009; 1: 5-9.
[2] Aletaha D. et al. 2010 Rheumatoid arthritis classification criteria// Arthritis Rheum 2010; 62 (9): 2569-81.

Disclosure of Interests: Tatiana Zybalova: None declared, Viktor Yagur: None declared, Roza Goncharova: None declared, Nikolaj Soroka Grant/research support from: JSC BIOCAD, Natalia Dostanko: None declared, Valery Apanasovich: None declared, Anastasiya Tushina: None declared DOI: 10.1136/annrheumdis-2020-eular.5739

\section{Adaptive immunity ( $T$ cells and $B$ cells) in rheu- matic diseases}

\begin{tabular}{l|l}
\hline AB0025 & B-CELL SUBSETS AS ADDITIONAL DIAGNOSTIC \\
TOOL FOR PRIMARY SJOGREN'S SYNDROME AND \\
SYSTEMIC LUPUS ERYTHEMATOSUS
\end{tabular}

S. Benevolenskaya ${ }^{1}$, I. Kudryavtsev ${ }^{2}$, M. Serebriakova ${ }^{3}$, I. Grigor'eva ${ }^{4}$, A. Budkova ${ }^{5}$, D. Zammoeva ${ }^{4}$, D. Motorin ${ }^{1}$, A. Zaritskey ${ }^{4}$, S. Lapin ${ }^{5}$, A. Maslyanskiy ${ }^{4}{ }^{1}$ Almazov National Medical Research Centre, SaintPetersburg, Russian Federation; ${ }^{2}$ Institute of Experimental Medicine, Saint-Petersburg, Russian Federation; ${ }^{3}$ Institute of Experimental Medicine, Saint-Petersburg, Russian Federation; ${ }^{4}$ Almazov National Medical Research Centre, Saint-Petersburg, Russian Federation; ${ }^{5}$ Pavlov First Saint Petersburg State Medical University, Saint-Petersburg, Russian Federation

Background: Systemic lupus erythematosus (SLE) and primary Sjögren's syndrome (pSS) are chronic complex disorders with an autoimmune background, multifactorial etiology, multiple circulating antinuclear antibodies and damage of various organs. SLE and pSS have several similar clinical and serological aspects; likewise, SLE and Sjögren's syndrome may coexist (so-called secondary Sjögren's syndrome). However, applied classification criteria do not differentiate SLE and pSS. It is known that humoral immunity plays significant part in pathogenesis of those diseases; hereby, we can expect imbalances in B cell subset frequencies during SLE and pSS.

Objectives: To investigate clinical utility of B cell subsets in distinguish SLE and pSS during diagnosis.

Methods: A total of 25 SLE patients, 25 SS patients and 49 healthy volunteers (HV) were included in the study. The diagnosis of SLE was performed according to the 2019 EULAR - ACR classification criteria, the diagnosis of pSS - according to the 2016 EULAR - ACR criteria. Phenotyping of blood B cell subsets was done using flow cytometry. Total peripheral blood $B$ cells were identified using $C D 19$ expression, distinct $B$ cell subsets were characterized by $\operatorname{lgD}, C D 38$ and CD27 expression. All of the statistical analysis of data was performed with STATISTICA Version 12.0 Inc. (USA). Results: We evaluated the percentages of circulating B-cell subsets using three major classification schemes based on the relative co-expression of either IgD/ CD38 (so-called "Bm1-Bm5" classification), IgD/CD27 and CD38/CD27. A discriminant analysis was performed for all B cell classifications. Analysis of CD38 and CD27 co-expression demonstrated most significant separation between patients with SLE and pSS (fig. 1). Moreover, discriminant analysis carried out by using a forward stepwise model demonstrated that the top significance was documented while assessing the percentage of plasmoblasts (CD27hiCD38hi), resting memory B-cells (CD27dimCD38low), mature active B-cells (CD27dimCD38dim), naive mature B-cells (CD27dimCD38low), as well as counting the absolute numbers of transitional B-cells (CD27lowCD38hi), model percent correct was 78,6\% ( $p<0,05$, tab.1).

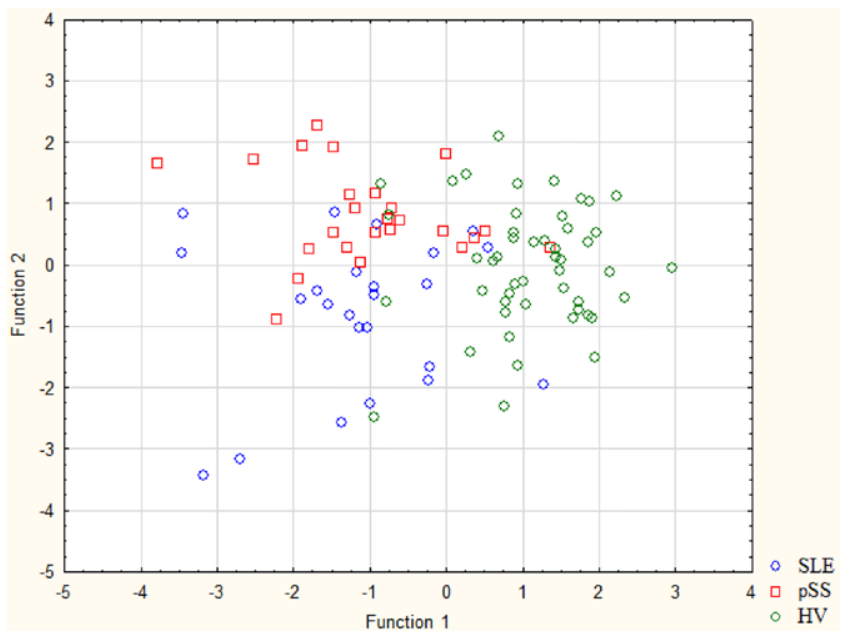

Figure 1. Graphic distribution of SLE and pSS patients as well as HV analyzed by discriminant analysis. 